Article

\title{
SMAP and CalCOFI Observe Freshening During the 2014-2016 Northeast Pacific Warm Anomaly
}

Jorge Vazquez-Cuervo', Jose Gomez-Valdes²

\section{Jet Propulsion Laboratory/California Institute of Technology \\ ${ }^{2}$ Physical Oceanography Department, Center for Scientific Research and Higher Education at Ensenada}

\begin{abstract}
Data from NASA's Soil Moisture Active Passive Mission (SMAP) and from the California Cooperative Oceanic Fisheries Investigations (CalCOFI) were used to examine the freshening that occurred during 2015-2016 in the Southern California Current System. Overall the freshening was found to be related to the 2014-2016 Northeast Pacific Warm Anomaly. The primary goal was to determine the feasibility of using SMAP data to observe the surface salinity signal associated with the warming. As a first step direct comparisons were done with salinity from the CalCOFI data at onemeter depth. During 2015 SMAP was saltier than CalCOFI by 0.5 PSU, but biases were reduced to $<0.1$ PSU during 2016. South of $33^{\circ} \mathrm{N}$, and within $100 \mathrm{~km}$ of the coast, SMAP was fresher in 2015 by almost 0.2 PSU. CalCOFI showed freshening of 0.1 PSU. North of $33^{\circ} \mathrm{N}$ SMAP and CalCOFI saw significant freshening in 2016, SMAP by 0.4 PSU and CalCOFI by 0.2 PSU. Differences between SMAP and CalCOFI are consistent with the increased stratification in 2015 and changes in the mixed layer depth.
\end{abstract}

Keywords: 1 Coastal; 2 Salinity; 3 Upwelling

\section{Introduction}

A well-documented marine heatwave occurred in the Northeast Pacific during the period 2014-2016 (hereafter known as the 2014-16 warm anomaly). Based on an analysis using NASA's multiscale ultra-high-resolution sea surface temperature (MUR SST), [1] reported that SST anomalies along the West Coast of the United States were warmer than usual during the period 2014-2016, relative to the 2002-2012 climatology. They found that during the upwelling season the anomalies were abated along the coast. As evidence of the regional effect of upwelling on the warming event, hydrographic data was used by [2] in finding that a strong upwelling event during the spring transition of 2015 abated the warm anomaly in Monterey Bay, California. [3] in their study of the pelagic ecosystem response of the 2014-16 warm anomaly off Oregon, found the same effect of the strong upwelling event. Based on underwater gliders observations and ancillary data products, [4] found that during 2014-2015 the warming of the Southern California Current System (Southern CCS) was a combination of high downward heat flux and weak winds, conditions that also lead to the stratification of the water column. At the same time as the 2014-16 warm anomaly, a strong El Niño event occurred. [5] analyzed the influence of the 2015-16 El Niño years on the CCS. They found that the effects of the equatorial Kelvin wave activity and the upwelling-favorable winds on the CCS were weaker than expected, especially for a strong El Niño. At the present time, a study of the salinity variability from remote sensing during the 2014-16 warm anomaly is lacking. 
The salinity signal associated with the 2014-2016 has been documented for some locations in the California Current domain by several authors. [3] showed evidences of negative salinity anomalies for both surface and subsurface waters off the slope/shelf waters off Oregon. [4] and [2] also found negative salinity anomalies off California. Recent results [6] have shown that salinity derived from the Soil Moisture Active Passive (SMAP) Mission can be used to detect changes in coastal waters associated with river discharge. In a study in the Gulf of Mexico, large signals in freshening were detected. The flooding event of 2015 in Texas caused an increase in river discharge which led to a freshwater plume in the Gulf of Mexico and significant freshening of greater than 5 Practical Salinity Units (PSU). Changes in salinity of this magnitude could potentially have impacts on the biology [7]. The work outlined here seeks to determine, using the SMAP data, the observed surface salinity signal during the 2014-2016. At the same time direct comparisons will be made with the CalCOFI data.

A key issue, because of the comparison of remote sensing derived surface salinity with insitu data, is how near-surface stratification can affect differences between the measurements. The issues were addressed by [8] where they examined possible differences between the two measurements due to evaporation, rain, and specific types of wind conditions. Under low wind speeds and high evaporation differences between one meter and the surface can reach at least 0.2 PSU. Thus, the interpretation of differences between remote sensing derived salinity and in-situ must be interpreted with respect to the known stratification. This is critical in interpreting the validation of the results.

California Cooperative Oceanic Fisheries Investigations (CalCOFI) is a successful and enduring monitoring program which includes a collection of hydrographic and biological data off the West Coast of North America. Since 1997 CalCOFI scientists have reported annually the State of the California Current. Their reports of 2015, 2016, and $2017 \quad[9,10,11]$ have shown that the CalCOFI data set is a very useful tool to study the hydrography of the 2014-2016 warm anomaly. The CalCOFI data has also been used to validate satellite products [12]. In particular, the CalCOFI hydrographic data set has been used to evaluate the importance of in situ salinity observations in heat storage estimation from satellite altimetry [13]. To evaluate the performance of SMAP sea surface salinity (SSS) during an open-ocean freshening event, this study compares SSS from SMAP with salinity (retrieved at one meter) from the CalCOFI array during the period 2015-2016. The variability of the freshening is examined along with explanations for differences between SMAP SSS and CalCOFI.

\section{Materials and Methods}

The work was divided into two major steps. The first step was directly comparing SSS derived from the SMAP Mission with salinity at 1-meter depth derived from the CalCOFI monitoring program. Hovmöller diagrams were derived from the SMAP SSS to examine the space-time variability. The second step was to derive Hovmöller diagrams from the CalCOFI hydrographic data to examine the space-time features of the freshening associated with the 2014-16 warm anomaly.

For step 1 comparisons were done directly between the SMAP SSS and the CalCOFI salinity at 1-m depth from April of 2015 through November of 2016. The data was co-located in space-time using a simple nearest neighbor approach. Because SMAP is in an 8-day repeat orbit the co-location window used was \pm 3 days and $25 \mathrm{~km}$. 
For the second step we examined the space-time evolution of the freshening associated with the 2014-16 warm anomaly. Hovmöller diagrams were derived. Latitude versus time diagrams of the SMAP SSS were used to determine the evolution of the freshening in the zonal direction. The resolution of the SMAP SSS $(40 \mathrm{~km})$ allowed for an examination of the time-space evolution of the signal along two longitudes: $118^{\circ} \mathrm{W}$, close to the coast, and at $120^{\circ} \mathrm{W}$, further from the coast. The rationale was to see if there were differences in the variability associated with the coastal upwelling signal compared to further offshore.

For step 3 an evaluation was done of the air-sea interaction effect on the salinity variations. Following [14] a simple model was applied to evaporation and precipitation satellite-derived data. Assuming a balance between the salinity changes at the sea surface and the precipitation minus evaporation rates, the salinity budget equation is in the form:

$$
\int_{-h}^{0} \frac{\partial S}{\partial t} d z=-S_{0}(P-E)
$$

where $h$, is the depth of the layer, $S_{0}$ is the mean surface salinity, and $P$ and $E$ are the precipitation and evaporation rates, respectively. In this work, $\mathrm{h}=1 \mathrm{~m}$.

Temperature and salinity anomalies at the surface (1-m) depth were examined at CalCOFI lines 76.7 (North), 83.3 (middle), and 90 (South), following the methodology of [15] and [16]. The mixed layer depth was calculated following [17] for the southern part of the California Current. The mixed layer depth anomalies were obtained following the same methodology as the one used with temperature and salinity. Every anomaly was obtained relative to the 2003-2012 climatology.

\subsection{Data}

\subsubsection{JPL SMAP Data}

The SMAP SSS data used in the study was the JPL version 3 product. The data was based on the Level 3 8-day running means gridded at 0.25-degree resolution. The SMAP product, at the time of the study, was available from April 2015 through the end of 2016. The dates used overlapped with the CalCOFI data from Spring 2015 to Fall 2016. More information on the data and its use may be found in the user's guide [18]. Because of the proximity of the study area to land, a brief review of the data and the correction for land contamination set is given below.

Level 3 products are generated from the Level 2 products using a Gaussian weighting. Weights are assigned based on the distance to the center of the given grid cell. The Level 3 product also contains the Hybrid Coordinate Ocean Model (HYCOM) as an ancillary field, which is shown in the study for comparison purposes. More information on the HYCOM model may be found at https://www.hycom.org. The HYCOM model does not assimilate CalCOFI data. Information on the assimilated parameters used may be found at: https://hycom.org/attachments/084 5 Lozano.pdf. 
Briefly, parameters assimilated include sea surface temperature from the Advanced Very High Resolution Radiometer (AVHRR), Geostationary GOES satellites, and sea surface height from the Jason satellite. Low frequency boundary conditions are relaxed to climatologies, including temperature and salinity. HYCOM is used for comparison purposes with the JPL SMAP product to determine the influence of land contamination on the SMAP SSS retrieval. This is critical in a study that attempts to use SMAP SSS data to examine coastal dynamics such as upwelling. The land contamination issue is explained as follows. Radiometers measure energy from the entire visible disk seen on the Earth's surface. If part of that disk lies over land, then the signal will partially include the brightness temperature generated by the land emissivity. In this case, the goal becomes to remove the signal due to land, leaving only the part due to the ocean. Corrections for land contamination are extremely important and need to be considered carefully when applying SMAP SSS to coastal studies.

To remove possible land contamination, the JPL SMAP product calculates a land climatology for the brightness temperature $\mathrm{Tb}$ at both the horizontal and vertical polarizations on a monthly time scale [18]. The climatology is then used to estimate the land contamination within $500 \mathrm{~km}$ of the coast. This is critical for deriving accurate SSS in the upwelling region off Southern California, which lies within $100 \mathrm{~km}$ of the coast. With the land correction, biases of SSS are reduced to -0.2 PSU with SSS being too fresh [18]. Beyond $50 \mathrm{~km}$ biases are reduced to near zero. Root Mean Square (RMS) differences are reduced to 0.5 PSU. Thus, the application of the land correction is critical for resolving the coastal SSS signal, where upwelling is expected to bring saltier deep water to the surface. Negative biases (fresher) near the coast would indicate possible land contamination.

\subsubsection{CalCOFI Data}

CalCOFI has made observations of the hydrography and biology off the West Coast of North America since 1949 and since 1984 has conducted quarterly cruises off Southern California. Data collected at depths down to 515 m include a Seabird 911 CTD mounted on a 24-bottle rosette with continuous measurements of pressure, temperature, and conductivity. CalCOFI CTD data are computed by Seasoft based on EOS-80. Salinity is PSS-78 (Practical Salinity Unit). Salinity values in the CalCOFI array are typically between 32-36 PSU, with of course the equivalency of PSS and PSU. More information on CalCOFI CTD general practices and algorithms may be found at http://www.calcofi.org/. Presented here is the time evolution of the seawater properties using data obtained during the 2003-2017 period. The modern CalCOFI salinity measurements provide a unique coastal data set that spans decades. Thus, the data will provide a validation of SSS during the overlap period of the SMAP mission.

\subsubsection{Evaporation Data}

Evaporation data was retrieved from the Woods Hole Oceanographic Institution Objectively Analyzed Air-Sea Flux data set [19]. More information on the data set may be retrieved from http://oaflux.whoi.edu.

\subsubsection{Precipitation Data}


Rain rate was extracted from the Special Sensor Microwave Imager (SSM/I) onboard the Defense Meteorological Satellite Program (DMSP) satellites since 1987. DMSP satellites are polar orbiting and listed by satellite number, F08 through F18. Rainfall data was downloaded from Remote Sensing Systems (http://www.remss.com/missions/ssmi/). More information on the processing and latest processing algorithms may be found in [20].

\section{Results}

\subsection{Validation of SMAP data}

The JPL SMAP data was directly compared/co-located with all the CalCOFI data to determine the overall quality and validate the data in the region. The data was also divided into sub regions for statistical comparisons to evaluate possible differences based on the proximity to the coast. Comparisons were also done with the HYCOM model as a third independent data set. The HYCOM model derived salinity is readily available as an ancillary field in the SMAP SSS. Comparisons are only shown for the JPL product.

Figure 1 shows the location of the CalCOFI lines used in the study. Along the coast, the CalCOFI monitoring program spans the California Coastline. The stations plan also extends several hundred kilometers offshore. We analyzed all the lines shown in the figure. We found that lines 76.7, 83.3, and 90 are a good representation of the variability at the northern, middle, and southern part of the CalCOFI region, respectively.

Figure 2 (a,b,c,d,e,f) shows the monthly averaged values for SMAP for (a) April 2015 , (b) April 2016, (c) July 2015, (d) July 2016, (e) November 2015, and (f) November 2016. The most prominent differences are clearly seen in July and November. July of 2015 clearly shows the saltier water along the coast associated with the seasonal upwelling. [16] outline three periods of upwelling off the Central to Northern California; April to June is associated with intensification of upwelling due to alongshore Equatorward Winds. July to September one sees a relaxation of the upwelling associated with the weakening of the alongshore winds. November through March is considered the storm season and a transitional period. These patterns are consistent with the variability seen in Figure 2. Thus, the observed seasonal cycle in the SMAP SSS is consistent with the historical analysis. November of 2016 shows fresher waters along the coast, specifically between $30^{\circ} \mathrm{N}$ and $35^{\circ} \mathrm{N}$. Overall the SMAP SSS shows freshening in 2016, with a clear impact along the coast and the upwelling signal. To our knowledge this is the first time salinity data from SMAP has been used to observe the coastal upwelling signal off California that is associated with the 2014-2016 warm anomaly. 


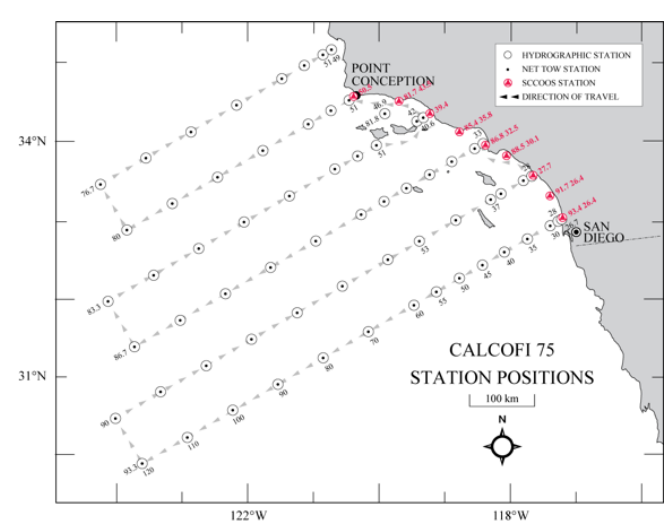

Figure 1. Location of the CaLCOFI 75 stations.

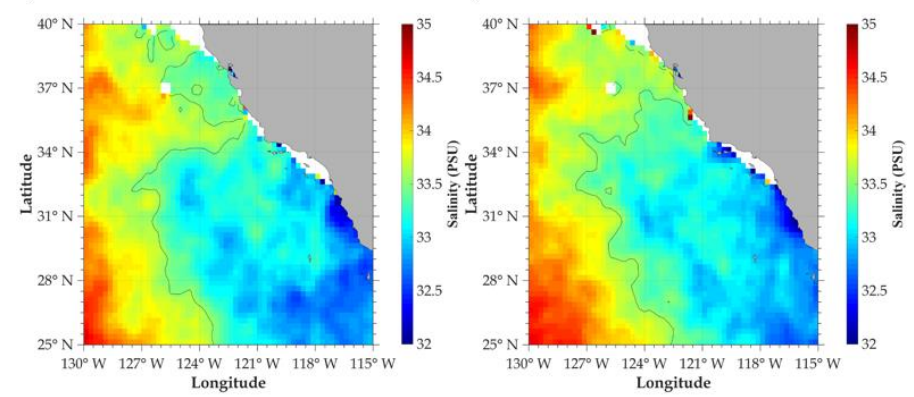

c)

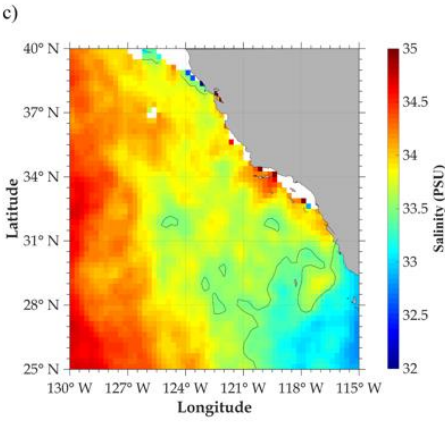

d)

e)
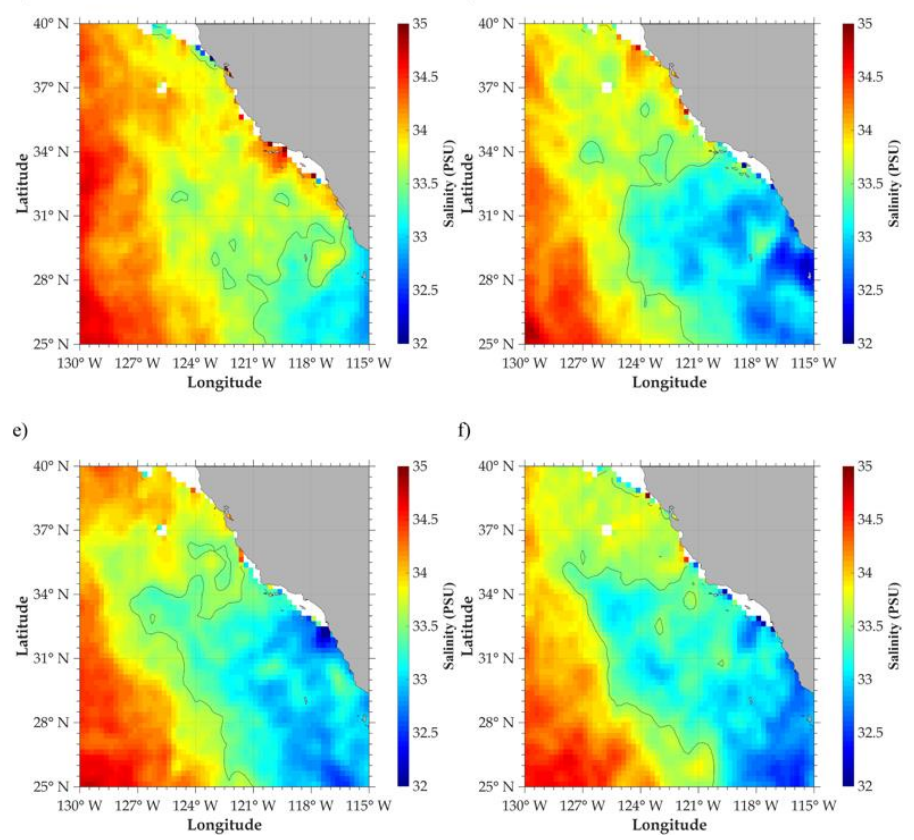

Figure 2. SMAP Monthly. a) map of SSS averaged from SMAP for April 2015; b) map of SSS averaged from SMAP for April 2016; c) map of SSS averaged from SMAP for July 2015; d) map of SSS averaged from SMAP for July 2016; e) map of SSS averaged from SMAP for November 2015; f) map of SSS averaged from SMAP for November 2016.

Figure $3(a, b)$ illustrates further the space-time variability of SSS from SMAP using Hovmöller diagrams at $120^{\circ} \mathrm{W}$ and $118^{\circ} \mathrm{W}$. At $120^{\circ} \mathrm{W}$ (further offshore) one clearly sees the 
propagation of freshwater from North to South. From April of 2015 through December of 2016 freshwater has propagated from $33^{\circ} \mathrm{N}$ to $25^{\circ} \mathrm{N}$. Closer to the coast at $118^{\circ} \mathrm{W}$ freshening is also observed, but the signal in 2015 is dominated by an annual/semiannual component, most likely due to the coastal upwelling signal. One still sees a semiannual component closer to the coast but localized further South at approximately $25^{\circ} \mathrm{N}$. The freshening has impacted the coastal waters and likely weakened the upwelling signal. The results are consistent with [1] and [2] in showing that the warming along the coast abated during spring upwelling season. Overall the results are consistent in showing that although the impacts of the warming were felt along Southern California, maxima impact of SST and SSS were seen north of $35^{\circ} \mathrm{N}$. To quantify and validate these results direct comparisons were first made with the salinity at 1-meter depth from the CalCOFI monitoring program.

Figure 4 (a) shows the mean SSS values over the entire CalCOFI region for April 2015, July 2015, November 2015, January 2016, April 2016, and November 2016. Over the entire region for 2015, values for SMAP SSS (red) are saltier than both HYCOM (blue) or CalCOFI (black). Values show SMAP SSS saltier by almost 0.4 PSU for 2015. In 2016 SMAP SSS and CalCOFI agree to less than 0.1 PSU. Over the entire CalCOFI region all three, SMAP, CalCOFI, and HYCOM show a freshening in 2016, but the freshening is magnified in SMAP. The freshening in SMAP is approximately 0.3 PSU while in CalCOFI and HYCOM the freshening is around 0.1 PSU. Figure 4 (b) shows the bias between SMAP-CalCOFI (black) and HYCOM-CalCOFI (blue). Biases between HYCOM-CalCOFI are consistently smaller than 0.1 PSU over the entire region. Biases defined as SMAP-CalCOFI show the saltier SMAP bias of 0.4 PSU for 2015 decreasing to less than 0.1 PSU in 2016. Thus, over the entire region, SMAP SSS was saltier than CalCOFI for 2015, almost reaching zero in 2016. Figure 4 (d) is the same as $4(\mathrm{~b})$, but for the area between $30^{\circ} \mathrm{N}$ and $33^{\circ} \mathrm{N}$ and $100 \mathrm{~km}$ from the coast. Close to the coast (Figure 4(c) in the Southern CCS region all three: SMAP, CalCOFI, and HYCOM show fresher values in 2015, becoming slightly saltier in 2016. This is consistent with upwelling conditions returning to normal in mid to late 2016. SMAP shows an increase in saltiness by about 0.2 PSU while CalCOFI and HYCOM show an increase of about 0.1 PSU. Figure 4 (e) shows the SMAP, CalCOFI, and HYCOM values for the region between $30^{\circ} \mathrm{N}$ to $35^{\circ} \mathrm{N}$ for the area greater than $100 \mathrm{~km}$ from the coast. All three data sets show an increase in freshening in 2016 with minimum values seen in April of 2016. However, the freshening in SMAP is even more pronounced, greater than 0.4 PSU. After April of 2016, all three data sets showed trends of increasing saltiness. Biases (Figure 4 (f)) are reflective of the saltiness of SMAP in 2016. Error bars in Figures 4 (b, d, and f) show consistent RMS differences that are reduced to less than 0.3 PSU for 2016. Overall biases between the HYCOM SSS and CalCOFI SSS were $<0.1$ PSU.

The saltier values of SMAP in 2015 may be understood in terms of the stratification of the water column. Previous studies comparing SMAP with ARGO data have shown there are no significant changes in the biases between 2015 and 2016 [21]. There is also no indication that such biases exist in the CalCOFI data. Thus, another explanation must be found for the observed differences between 2015 and 2016. This will be discussed further in the next section. Overall results using the CalCOFI data showed increased stratification of the water column in 2015, with saltier 

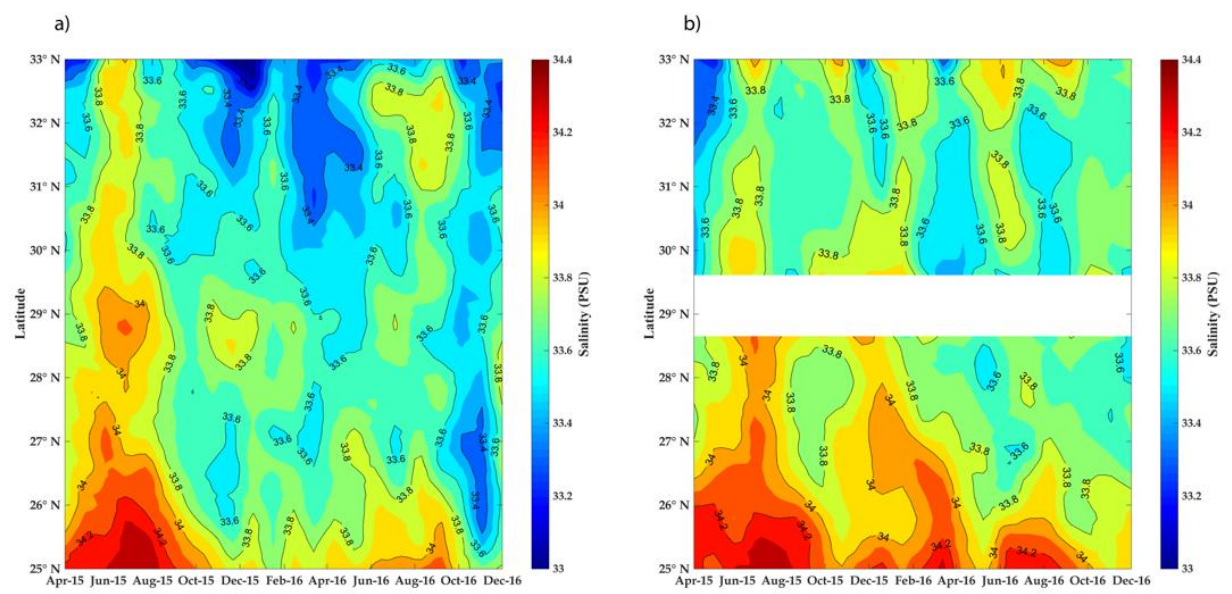

Figure 3. Hovmöller diagrams using SMAP derived SSS of the latitudinal variation at two (a) $118^{\circ} \mathrm{W}$ and b) $120^{\circ} \mathrm{W}$ ) longitudes.
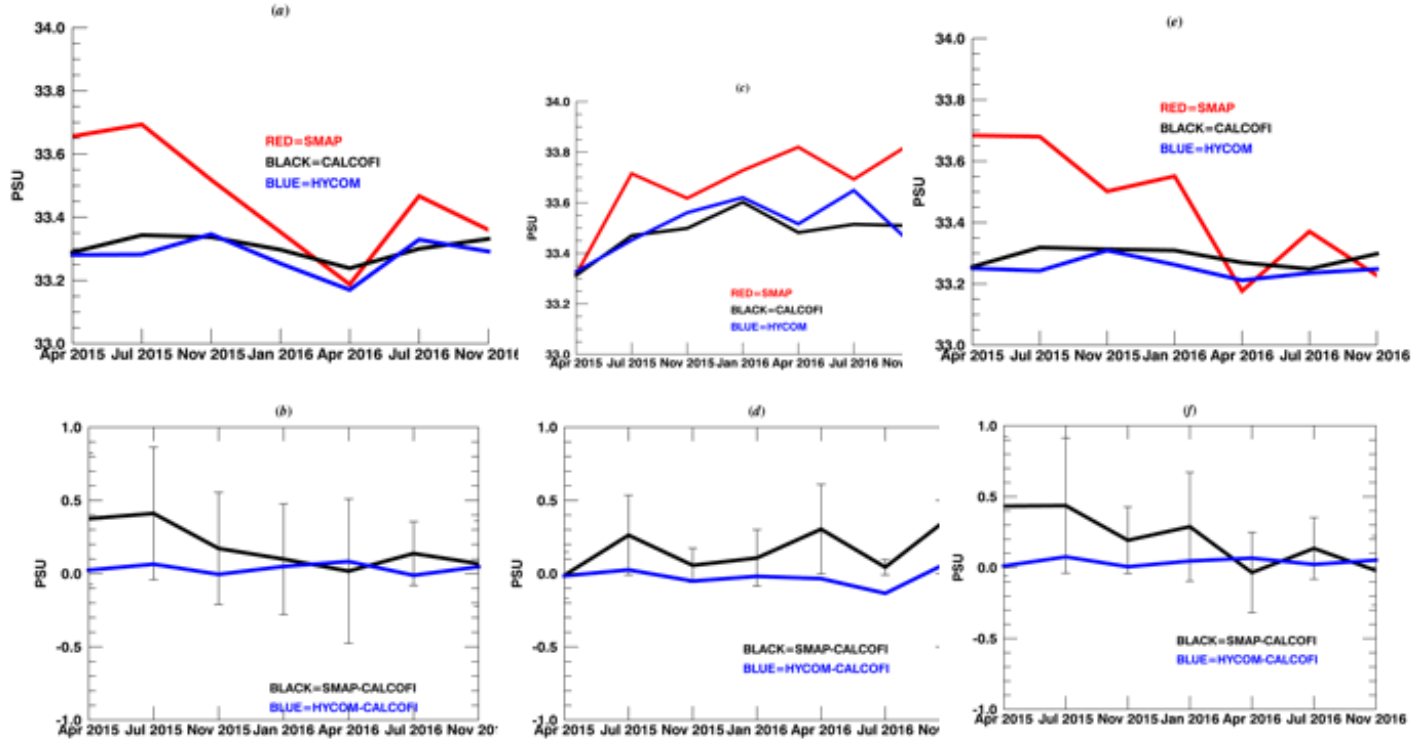

Figure 4. (a,b,c,d,e,f). a) Shows SSS averaged at CalCOFI for all locations between $25^{\circ} \mathrm{N}$ to $40^{\circ} \mathrm{N}$ and $130^{\circ} \mathrm{W}$ to $115^{\circ} \mathrm{W}$, red=SMAP, black=CalCOFI, and blue=HYCOM. b) Shows bias and rms over all the CalCOFI lines for SMAP-CalCOFI (black) and HYCOM-CalCOFI (blue). c) Same as a), except for $30^{\circ} \mathrm{N}$ to $33^{\circ} \mathrm{N}$ and greater than $100 \mathrm{~km}$ off the coast. d) same as b), except for $30^{\circ} \mathrm{N}$ to $33^{\circ} \mathrm{N}$ and within $100 \mathrm{~km}$ of the coast. e) same as a), except for $33^{\circ} \mathrm{N}$ to $35^{\circ} \mathrm{N}$ and greater than $100 \mathrm{~km}$ of the coast. f) same as b), except $33^{\circ} \mathrm{N}$ to $35^{\circ} \mathrm{N}$ and within $100 \mathrm{~km}$ of the coast.

biases in SMAP as a result of the stratification. Biases of 0.2-0.3 PSU are consistent with those reported by [9]. 


\subsection{Salinity variations induced by precipitation and evaporation}

Table 1 shows the year-to-year salinity changes associated with the rate of change of precipitation minus evaporation factor. The maximum salinity change occurred in Fall and the minimum in Summer. Because the evaporation rate was greater than precipitation rate the salinity changes are mainly associated with the former. Table 1 reveals that the salinity changes in 2015 induced by the evaporation reached -0.6 PSU in April of 2015 and greater than -2.2 PSU in November. The results are consistent with the saltier values derived from SMAP in 2015. The increased evaporation is also consistent with the increased stratification in 2015. This will be discussed more in later sections.

Table 1. Year-to-year salinity changes.

\begin{tabular}{|l|l|}
\hline Month & $2015-2016$. Units are UPS. \\
\hline January & -1.3 \\
\hline April & -0.6 \\
\hline July & 0.1 \\
\hline November & -2.2 \\
\hline
\end{tabular}

\subsection{CalCOFI Observations}

Figure 5 shows the histograms of the salinity distribution for the coastal zone at 1-m depth for the four year period 2013-2016. In 2013, the range of salinity was between 33.2-33.6 UPS with a skewness of -0.50 and a kurtosis of 4.9 , while the median stood at 33.6 UPS. In the next year, the range of the salinity was the same as the past year, the skewness was -1.12, and the kurtosis was 5.1. In the following year, the range changed. The skewness value decreased to -1.30 , and the kurtosis increased to 10.6, with the median decreasing to 33.3 UPS. Finally, in 2016, the range of salinity was between 32.7-33.6 UPS, the skewness was - 2.4, the kurtosis was 10.0, and the median was 33.5 UPS. The 2013-2014 period was saltier than the 2015-2016 period. It is also worth mentioning that the kurtosis was higher in the second period (2015-2016).

Figure 6 shows the histograms of the salinity's distribution for the oceanic zone at 1-m depth for the same 4 year period. In 2013, the range of salinity was between 33.9-33.6 UPS with a skewness of 0.30 and a kurtosis of 3.5, while the median stood at 33.3 UPS. In the next year, the range of the salinity was between 33.0-33.6 UPS with a skewness of 0.18, the kurtosis decreased to 2.4, and the median did not change. In the following year, the range changed to 32.8-33.6 UPS, the skewness was -0.13 , and the kurtosis increased to 2.3 , In this case the median decreased to 33.2 UPS. Finally, in 2016, the range of salinity was between 32.6-33.6 UPS, the skewness was - 0.25 , the kurtosis was 2.8, and the median decreased to 33.1. For the oceanic zone these histograms show clearly the freshening from 2013-2014 that extended into 2015-2016. 
CalCOFI data at 1-m depth observe the 2014-2016 warm anomaly (Figure $7(a, c, e)$ ). In the CalCOFI region, the warming started in 2014 and was most pronounced in 2015 when the positive anomalies were around $4{ }^{\circ} \mathrm{C}$.

The geographic distribution of SSS anomalies in the CalCOFI region was irregular during the period 2014-2016 (Figures 7 (b,d,f)), which is an indication that SSS was responsive to local dynamics and air-sea fluxes. Near the coast, negative SSS anomalies prevailed in 2015 at the three CalCOFI
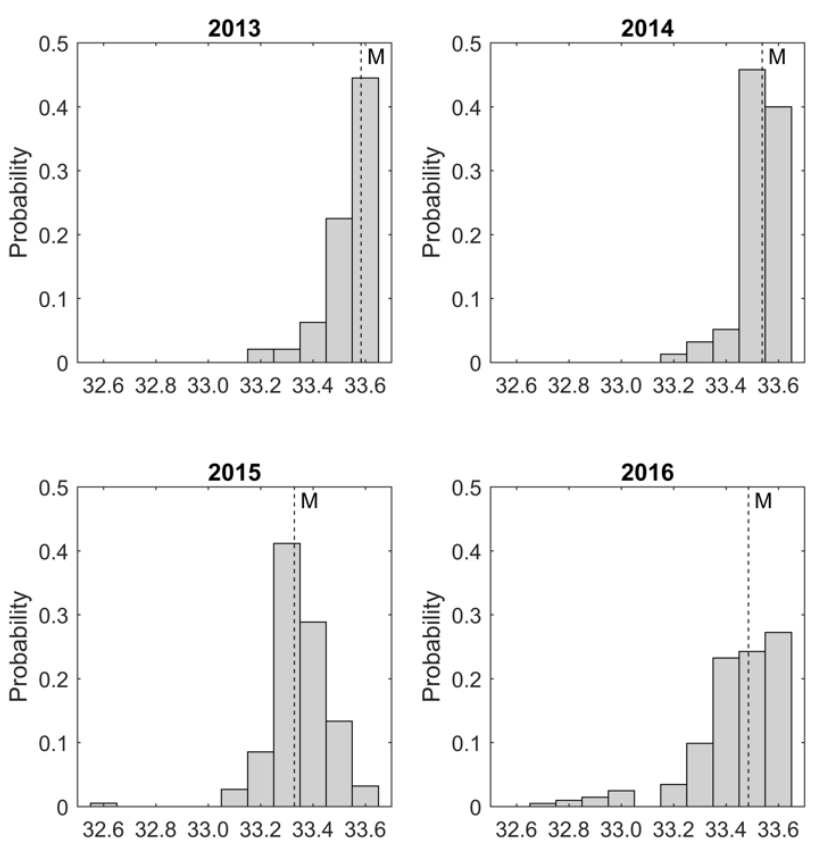

Figure 5. Histograms of salinity at 1-m depth for the coastal zone of the CalCOFI sampling region: 2013, 2014, 2015, and 2016. The dashed line indicates the median of the distribution. 

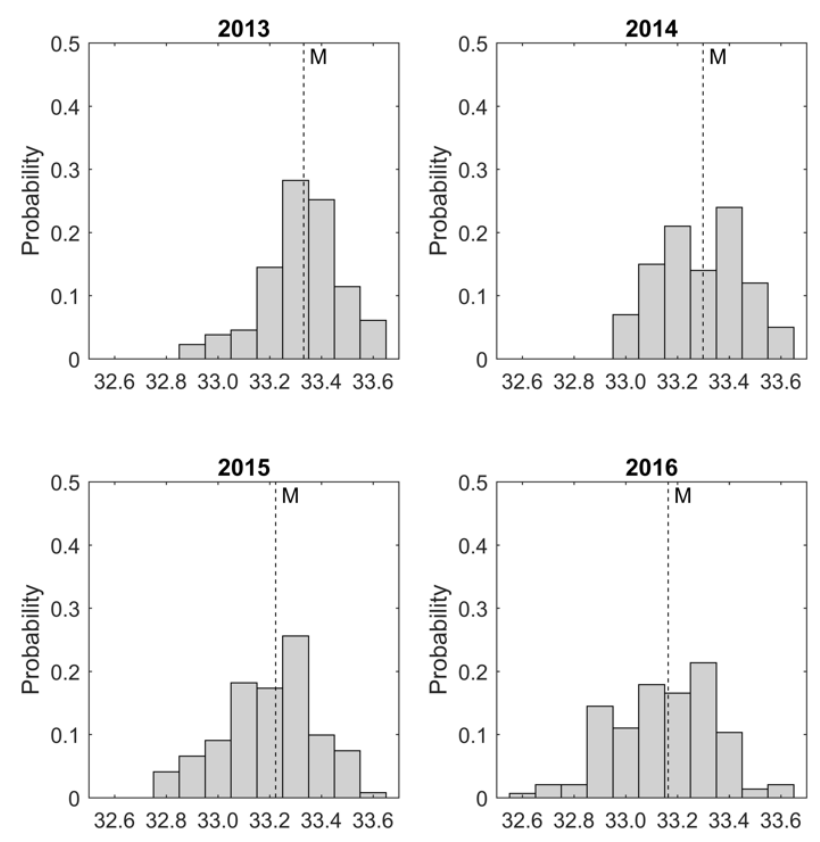

Figure 6. Same as 5, except for the oceanic zone.

lines. In the northern part of the CalCOFI region (Line 76.7), negative SSS anomalies (less than - 0.2 PSU) occurred in 2016 almost over the entire line, while for the rest of the CalCOFI lines negative SSS anomalies were of lesser magnitude. The minimum anomaly (-0.4 PSU) occurred in 2016 along Line 76.7. The freshening associated with the 2014-16 warm anomaly was evident in the SSS anomalies.

The mixed layer depth (MLD) is an indication of the degree of stratification, the smaller the MLD the greater the stratification. During the 2014-2106 warm anomaly, MLD was overall anomalously negative in the CalCOFI region (Figure $8(a, b, c)$ ). At Line 76.7 the negative MLD anomalies prevailed during 2014-2015, when the highest number of negative anomalies occurred further from the coast. In exchange the negative anomalies occurred near to coast in 2016. As for Line 83.3 the negative MLD anomalies also prevailed during 2014-2015 but not in the winter season. Meanwhile at Line 90 the negative MLD anomalies were less abundant than the other lines. 
a)

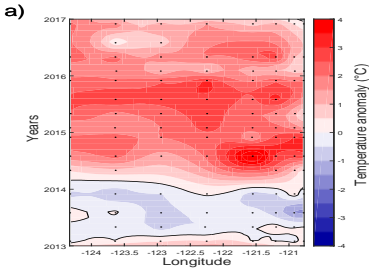

c)
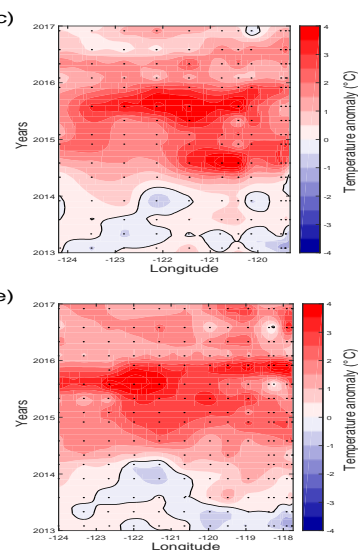

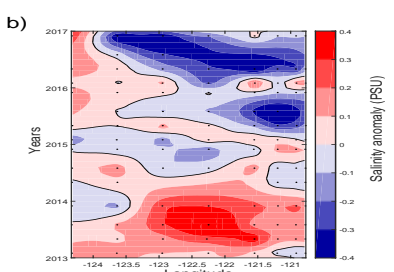

d)
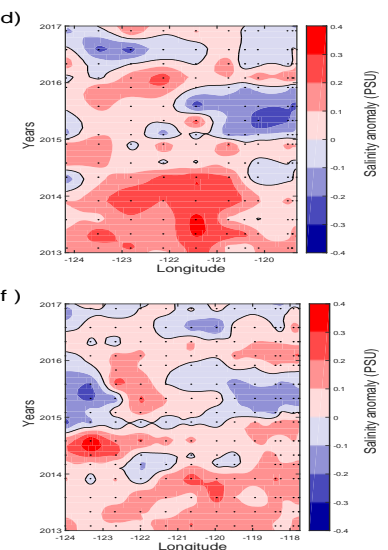

Figure 7. (a,b,c,d,e,f). Hovmöller diagrams of temperature anomalies $\left({ }^{\circ} \mathrm{C}\right)$ at $1-\mathrm{m}$ depth for lines 76.7 (a), 83.3 (c), and 90 (d), and salinity anomalies (UPS) at 1-m depth for lines 76.7 (b), 83.3 (e), and 90 (f). The anomalies are relative to the 2003-2012 climatology.

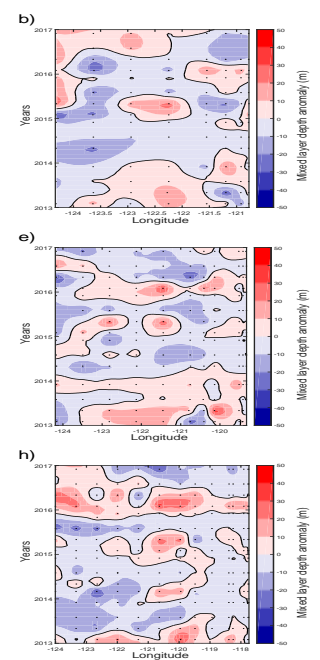

Figure 8. $(a, b, c)$. Hovmöller diagrams of mixed layer depth anomalies $(m)$ for lines $76.7(a), 83.3(b)$, and 90 9c). The anomalies are relative to the 2003-2012 climatology. 
1. Discussion

Results show both the surface salinity signal as measured by SMAP and the $1 \mathrm{~m}$ salinity signal as determined by CalCOFI during the 2014-16 warm anomaly [1,3]. Unique results are presented using SMAP SSS to observe the variability of salinity in a coastal region. Results are consistent with the CalCOFI monitoring program and the known stratification during that period of time.

Freshening was observed in the CalCOFI region throughout 2015 and 2016. The freshening was observed greater than $100 \mathrm{~km}$ from shore in both the CalCOFI and SMAP data. In the SMAP SSS, freshening offshore appears in 2015, spreading throughout the entire region in 2016. Offshore SMAP SSS shows freshening of 0.5 PSU starting in the North in 2015 but then extending South through 2016. The magnitude of the freshening, approximately 0.5 PSU, is most likely driven by the increased stratification in 2015. The stratification is consistent with MLD derivations for the same time period. Freshening is also observed in the CalCOFI lines but at a decreased magnitude. Maximum freshening appears at Line 76.7 (North) in 2016 with anomalies, based on the CalCOFI climatology at one-meter depth, reaching 0.4 PSU. Further south freshening is reduced with anomalies of 0.2 PSU appearing along the coast in 2015. The differences in SMAP SSS and CalCOFI salinity between 2015 and 2016 can be explained by the stratification of the water column. Stratification occurred in 2015 and 2016 but had a maximum in 2015. Biases between SMAP SSS and CalCOFI were larger than 0.4 PSU during 2015 but reduced to less than 0.1 PSU in 2016. The difference is consistent with the increased stratification in 2015. Results are consistent with [4], who showed that during the 2014-15 period local anomalous heat flux and wind strength led to the warming in the region. During the period of greater mixing and decreased stratification differences between the SMAP SSS and CalCOFI were minimal. The stratification is consistent with increased evaporation rates in 2015 and changes in surface salinity.

Close to shore, within $100 \mathrm{~km}$, both SMAP and CalCOFI show a trend towards saltier values between 2015 and 2016. This is consistent with the increasing strength of the upwelling signal in 2016. Results are consistent with [1] and [2].

Results are extremely important in showing that both satellite-derived SSS and in-situ salinity are needed to monitor changes in the stratification of the water column associated with air-sea interactions. There are predominately two reasons for this. First satellites measure a response at the surface of the ocean, while in-situ measurements are at depth. Thus, differences between the two measurements would reflect the stratification of the water column as they are related to the air-sea coupling. Second validation using in-situ data is important in assessing the quality of the satellite data. Once validated the satellites give enhanced spatial and temporal coverage not possible with in-situ data. Off the California Coast upwelling scales, along with fronts, can change on weekly to monthly time scales. The agreement between SMAP SSS and CalCOFI in the region is very encouraging for using SMAP SSS in coastal regions. Biases of less than 0.1 PSU would allow for monitoring of changes in salinity in critical ocean regions associated with coastal upwelling. SMAP is consistent in showing that near the coast freshening was minimized. In 2015, the observed signal in freshening is consistent with a weakening of coastal upwelling $[1,3]$.

Overall, direct comparisons between the SMAP SSS and salinity derived from the CalCOFI array showed biases were observed with the SMAP SSS saltier than CalCOFI for 2015. During 2016 biases between SMAP SSS and CalCOFI were reduced to less than 0.1 PSU. One of the goals of the work was to determine the primary reason behind the observed differences between 
2015 and 2016 and relate them to salinity differences between SMAP and CalCOFI caused by possible ocean conditions.

The 2015 differences between SMAP SSS and CalCOFI were found to be associated with the stratification of the water column. Based on the derivation, Figure 8 indicates a stronger stratification in 2015, consistent with an increase in salinity at the surface observed by the SMAP satellite. Differences in salinity between the two measurements are consistent with results in [8].

\section{Conclusions}

Several key results were found from using the SMAP SSS. Overall this should be considered an important step forward in applying satellite derived salinity to coastal processes and their connection to basin-scale changes. In summary:

- SMAP SSS can be used to monitor the freshening in a coastal region associated with a major warming event.

- $\quad$ SMAP SSS identifies changes in salinity associated with a coastal upwelling system.

- Coastal station-based programs, such as CalCOFI, are critical for fully understanding and validating satellite-derived SSS. In period of low stratification biases between the SMAP derived SSS and CalCOFI were less than 0.1 PSU increasing to greater than 0.4 during periods of high stratification.

Parameters that identify the air-sea coupling are critical for a comprehensive understanding of the differences between satellite derived and in-situ surface salinities. This study shows that in-situ data is not only needed for validation purposes but also to fully understand the issues of stratification and mixing that may lead to differences between satellitederived SSS and buoy salinity. Using both SMAP and CalCOFI lead to further evidence of the increased stratification during the 2014-2016 Northeast Pacific Warm Event.

Future research should focus on validation efforts of SMAP in other coastal regions where upwelling is pronounced. This includes the Peru/Chile Coast, Canarias, Benguela, and Western Australia.

Funding: The lead author was funded through a contract with the National Aeronautics and Space Administration at the Jet Propulsion Laboratory/California Institute of Technology. Professor Jose GomezValdes carried out the work while on sabbatical at the Jet Propulsion Laboratory/California Institute of Technology from the Centro de Investigación Científica y de Educación Superior de Ensenada, Baja California. CONACyT supported the preparation of this paper through contract \# 257125 to Gomez-Valdes. Luis E. Miranda provided computing assistance.

Acknowledgments: The SMAP data is accessible through the Physical Oceanography Distributed Active Archive Center (PO.DAAC) (https://podaac.jpl.nasa.gov/dataset/SMAP_PL_L23_SSS_CAP_8DAYRUNNINGMEAN_V3?ids=\&values=\&search=SMAP). CalCOFI data is available through http://calcofi.org/data.html.

Conflicts of Interest: The authors declare no conflict of interest. 


\section{References}

1. Gentemann, C. L., M. L. Fewings and M. Garcia-Reyes (2016). Satellite sea surface temperature along the West Coast of the United States during the 2014-2016 northeast Pacific marine heat wave. Geophysical Research Letters, 44, 312-319. doi:10.1002/2016GL071039.

2. Ryan et al. (2017). Causality of an extreme harmful algal bloom in Monterey Ba, California, during the 2014-2016 northeast Pacific warm anomaly. Geophysical Research Letters, 44, 5571-5579. doi:10.1002/2017GL072637.

3. Peterson, W.T., J. L. Fisher, P. T. Strub, X. Du, C. Risien, J. Peterson, and C. T. Shaw (2017). The pelagic ecosystem in the Northern California Current off Oregon during the 2014-2016 warm anomalies within the context of the past 20 years. Journal of Geophysical Research: Oceans, 122, doi:10.1002/2017JC012952.

4. Zaba, K.D. and D. L. Rudnick (2016). The 2014-2015 warming anomaly in the Southern California Current System observed by underwater gliders. Geophysical Research Letters, 43, 1241-1248. doi:10.1002/2015GL067550.

5. Jacox, M. G., E. L. Hazen, K. D. Zaba, D. L. Rudnick, C. A. Edwards, A. M Moore and S. J. Bograd. (2006). Impacts of the 2015-2016 El Niño on the California Current System. Early assessment and comparison to past events. Geophysical Research Letters, 43, 7072-7080. doi:10.1002/2016GL069716.

6. Fournier, S., J. T. Reager, T. Lee, J. Vazquez-Cuervo, C. H. David, and M. M. Gierach (2016),SMAP observes flooding from land to sea: The Texas event of 2015, Geophysical Research Letters, 43. doi:10.1002/2016GL070821.

7. Pares-Escobar, F, B. E. Lavaniegos and I. Ambriz-Arreola (2018). Interannual variability in oceanic euphausiid communities off the Baja California western coast during 1998-2008, Progress in Oceanography, 160, 53-67. doi: 10.1016/j.pocean.2017.11.009.

8. Boutin, J., et al. (2016), Satellite and in situ salinity: Understanding near-surface stratification and sub-footprint variability, Bull. Am. Meteorol. Soc. doi:10.1175/BAMS-D15-00032.1.

9. Leising et al. (2015). State of the California Current 2014-15: Impacts of the warm-water "Blob". California Cooperative Fisheries Investigations Reports, 56, 31-68. 
10. McClatchie et al. (2016). State of the California Current 2015-16: Comparisons with the 1997-98 El Niño. California Cooperative Fisheries Investigations Reports, 57, 5-61.

11. Welles et al. (2017). State of the California Current 2016-17: Still anything but "normal" in the north. California Cooperative Fisheries Investigations Reports, 58, 1-55.

12. McClain, C. R. (2008). A decade of satellite ocean color observations. Annual Review of Marine Science. 1, 19-42. https://doi.org/10.1146/annurev.marine.010908.163650

13. Sato, O. T., P.S. Polito and W. T. Liu (2000). Importance of salinity measurement in the heat storage estimation from TOPEX/POSEIDON. Geophysical Research Letters. 27, 549551.

14. Feng, M., P. Hacker and R. Lukas (1998). Upper ocean heat and salt balances in response to a westerly wind burst in the western equatorial Pacific during TOGA COARE. Journal of Geophysical Research, 103, C5, 10289-10311.

15. Bograd, S. J. and R. J. Lynn, (2003). Long-term variability in the Southern California Current System. Deep-Sea Research II, 50, 2355-2370. doi:10.1016/S0967-0645(03)00131-0.

16. Garcia-Reyes, M. and J. L. Largier (2012). Seasonality of coastal upwelling off central and northern California: New insights, including temporal and spatial variability. Journal of Geophysical Research, 117, C03028. doi:10.1029/2011JC007629.

17. Torres. H. S. and J. Gomez-Valdes. (2015). Coastal Circulation driven by short-period upwelling-favorable winds in the northern Baja California region. Deep-Sea Research. Part I. 98, 31-42. doi.org/10.1016/j.dsr.2014.12.003.

18. Fore, A., S. Yueh. W. Tang and A. Hayashi (2016). SMAP Salinity and Wind Speed Data User's Guide, V3, Jet Propulsion Laboratory/California Institute of Technology.

19. Yu, L., J. Xiangze and R. A. Weller (2008). Multidecadal Global Flux Datasets from the Objectively Analyzed Air-sea Fluxes (OAFlux) Project: Latent and Sensible Heat Fluxes, Ocean Evaporation, and Related Surface Meteorological Variables (OAFlux Project Technical Report OA-2008-01). Woods Hole Oceanographic Institution, Woods Hole, MA, $64 \mathrm{pp}$. 
20. Wentz, F. J. (2013)._SSM/I Version-7 Calibration Report (RSS Technical Report 011012). Remote Sensing Systems, Santa Rosa, CA, 46 pp.

21. Tang, W., A. Fore, S. Yueh, T. Lee, A.Hayashi, Sanchez-Franks, J. Martinez, B. King and D. Baranowski (2017). Validating SMAP SSS with in-situ measurements,

Remote Sensing of Environment, 200, 326-340. doi: 10.1016/j.rse.2017.08.021. 